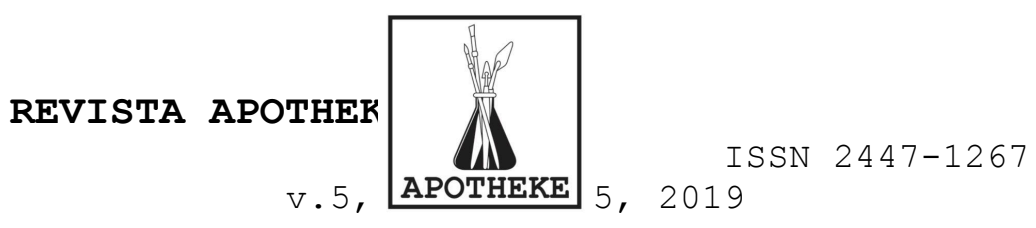

\title{
Desenho e linha: modos de Pensamento e Expressão
}

\author{
Flávia de Lima Duzzo (UDESC)
}

\begin{abstract}
RESUMO
Neste artigo são apresentadas algumas considerações sobre o conteúdo abordado no segundo capítulo da minha tese ${ }^{1}$, que se estende às questões da linha no seu âmbito geral e no específico do desenho, bem como uma reflexão sobre o ato de desenhar. O estudo envolve o tema do desenho como sendo um meio direto de expressão, e a presença da linha atuando na ordenação do nosso pensamento abstrato. Questiona-se em que medida a proximidade com o desenho no dia a dia, quer pelo seu caráter de anotação ou orientação, poderia ativar a sua prática como meio de criação nas artes. Finalizo, apresentando três artistas contemporâneos que trabalham a problemática da linha na expansão do campo do desenho.
\end{abstract}

PALAVRAS CHAVE: Linha; Desenho; Extensão do Pensamento; Expressão

\section{ABSTRACT}

This paper addresses some considerations about the content approached in the second chapter of my thesis, which extends to the questions of the line in its general scope and in the specific one of the drawing. The study involves the theme of drawing as being a direct means of expression and the presence of the line acting in the ordering of our abstract thinking. It is questioned to what extent the proximity with the drawing in the day to day, by its character of annotation or orientation, could activate its practice as a means of creation in the arts. I conclude by presenting three contemporary artists who work on the problematic of the line in the expanded field of drawing.

KEY WORDS: Line; Drawing; Extension of Trought; Expression.

Desenhar engloba um processo mental e físico, cuja articulação acontece de forma quase instantânea. O desenho, por seu caráter imediato em plasmar uma ideia e pela simplicidade de seus instrumentos, tem sido um meio propício para expressar pensamentos e sentimentos. Os procedimentos que adotamos para desenhar se assemelham em alguns aspectos aos da escrita como, por exemplo: a condução da linha sobre uma

1 Ausências no Desenho: áreas de não-desenho, apagamento e desgaste. Defendida em outubro de 2014 - ppgav-UFRGS.

DOI : $10.5965 / 24471267522019101$

http://dx.doi.org/10.5965/24471267522019101 
REVISTA APOTHEK

superfície, o tipo de manualidade empregada, assim como o seu caráter de anotação.

Nesse estudo me atenho a analisar as propriedades da linha com o intuito de refletir sobre a sua presença como elemento do desenho e seu potencial de ordenar os pensamentos, considerando que essa conduta permitirá melhor aprofundamento da pesquisa. O foco desse estudo recai unicamente sobre um dos elementos do desenho: a linha, cuja atuação reflete nas artes e na ordenação do nosso pensamento cotidiano. Com isso, pretendo verificar se a proximidade das nossas ações e pensamentos, apoiados na linearidade poderia, de alguma forma, desconstruir certo entrave no que tange ao ato de desenhar.

Cabe aqui ressaltar que não desconsidero a visão apresentada por Walter Benjamin em seu ensaio do ano de 1917, intitulado: Sobre a Pintura ou Sinal e Mancha, de que o desenho é a inter-relação da linha com a superfície que a acolhe.

Certas especificidades do desenho serão igualmente apresentadas, com o intuito de refletir sobre o lugar do desenho na arte e nas obras de alguns artistas contemporâneos que trabalham com a expansão desse meio.

\section{A LINHA NUM SIGNIFICADO AMPLO}

A presença de uma linha sempre provocará alteração no local onde se instaura, podendo unir e agregar e também segmentar ou isolar partes. Por um lado, ela pode ser utilizada para separar através da delimitação de áreas e, por outro, ligar regiões distantes tal qual se pode ver, por exemplo, em vistas aéreas. Utilizamos a linha em nossas vidas. Quando pensamos em nos deslocarmos de um lugar a outro, imaginamos um trajeto linear que nos forneça a orientação de onde ir. 
REVISTA APOTHEK

As definições de linha que encontramos em dicionários da língua portuguesa se estendem a diversas áreas do conhecimento, justamente por ela estar presente em vários âmbitos de nossas vidas. A acepção substantiva de linha aparece associada à ideia de fio: 'fio de fibras torcidas de linho, algodão, seda, sintéticas, etc., usado em costuras, bordados, rendas, etc.'). No sentido figurado, por exemplo: andar na linha (proceder de forma conveniente); manter a linha (manter o peso, a elegância); sair da linha (comportar-se de maneira não conveniente). Relativo à geometria, uma das definições que encontramos é: 'traço contínuo, alongado, real ou imaginário, representativo de uma extensão que se considera hipoteticamente como não tendo largura nem altura, apenas comprimento' (HOUASSIS,2009, p. 1184).

Leonardo da Vinci apresentou em seu caderno de notas a seguinte definição sobre a natureza da linha:

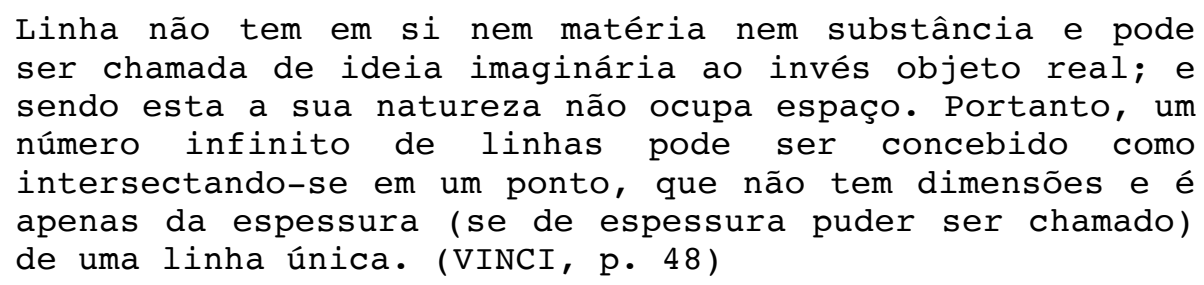

Percebe-se que o comentário de Leonardo Da Vinci sintoniza a uma das acepções do vocábulo linha na geometria, encontrada nos dicionários: a consideração da sua quase imaterialidade.

A linha, muitas vezes, serve como tradutora de fenômenos difíceis de serem mensurados por nossos sentidos. O traçado de um eletrocardiograma, por exemplo, vale-se de oscilações lineares para cima ou para baixo em um eixo (y), representando, assim, a variação dos batimentos cardíacos ao longo do tempo $(\mathrm{x})$. As ondas sonoras, também, estão graficamente representadas em suas oscilações através de processo semelhante (amplitude versus tempo). 
REVISTA APOTHEK

Outro artifício do qual nos valemos para organizar a nossa percepção é o de considerarmos que o encontro da superfície terrestre com o céu é uma linha, a qual denominamos de horizonte. Essa é uma linha virtual, não está nem inscrita nem instaurada no local onde atribuímos a sua presença. No encontro de dois planos, nosso olhar codifica seus limites como sendo uma linha. Este tipo de tradução é amplamente utilizado, justamente, pela nossa necessidade de identificar elementos separadamente.

\section{LINHAS DO DESENHO}

No âmbito da arte, Alfred Brooks ${ }^{2}$ apresenta sua concepção na qual considera que a linha, assim como as palavras, é uma convenção. Ao observarmos um desenho, vemos que onde uma forma inscrita acaba, ali começa o fundo e nesta fronteira surge uma necessidade de ordenação da imagem através da linha. Na argumentação de seu ponto de vista, o autor utiliza como exemplo duas possibilidades de percepção na representação gráfica de um lírio. Um lírio que é segurado contra um fundo de folhas e outro sobre um fundo de papel preto. Em ambas as situações o que se vê é a forma do lírio, mas se nos dois casos pararmos de olhar para a flor, veremos folhas ou o papel preto. Quando deixamos de ver o lírio, vemos o fundo (em um caso as folhas, no outro a área preta) e não uma linha de contorno delimitando a forma da flor.

A flor não é definida pela linha, mas o homem, com o fim de transmitir uma impressão da forma da flor e para nos dizer quais são seus limites e onde o fundo começa, teve em mente, fazer uso da convenção de linha, isto é, ele desenhou a forma do lírio com linha, com algo que não podemos ver na natureza porque não existe ali. Esta é uma convenção, mas é uma convenção que pode transmitir muito do fato e muito do seu significado, e nas mãos do

2 Alfred Brooks (1870-1963). Historiador e professor de artes na Indiana University-EUA. 
REVISTA APOTHEK

artista ser o meio de gravar a beleza consumada em forma de verdade. (BROOKS, 1920, p. 142)

A concepção de Brooks sobre a propriedade da linha em delimitar áreas afina-se com a noção apresentada no parágrafo anterior: seu uso como elemento capaz de auxiliar na decodificação do que escapa a nossa capacidade de percepção, entendimento, reconhecimento e orientação.

Brooks, referindo-se especificamente à linha do desenho, apresenta a seguinte conceituação: "Desenho significa aquilo que é deixado quando um instrumento, caneta ou lápis, é arrastado sobre um pedaço de papel. Esse 'algo' é uma linha". (BROOKS, 1920:137). Brooks parece considerar a linha desenhada como um resto, a sobra da ação que conduziu o instrumento sobre a superfície. Sua visão, nesse sentido, dialoga com os aspectos de leveza e fluidez nas linhas que encontramos em muitos desenhos.

Alguns dos verbos utilizados pelo autor para caracterizar o modo de conceber linhas no desenho: conduzir, arrastar, movimentar, percorrer, referem-se a ações que estão ligadas ao percurso de trajetos, caminhos ou rotas. Decorre da noção desses verbos o sentido de 'deslizamento', termo ligado à ideia de um deslocamento no qual há pouco atrito. Ao buscarmos um deslizamento do instrumento de desenho sobre a superfície que será riscada, intenciona-se diminuir ao máximo o entrave que poderia se impor a este fazer, o que de certa forma é reiterar um dos sentidos do desenho: um meio que é direto e por isto tão adequado para expressar pensamentos e mesmo emoções. Atentando ao seu potencial de síntese, percebe-se que a diminuição do trabalho mecânico, decorrente do 'arrastar' e 'deslizar', requer um raciocínio laborioso. Ademais, sintetizar procede de uma elaborada operação intelectual, uma vez que dá conta de plasmar formas ou conteúdos complexos de maneira resumida, pressupondo um conhecimento e entendimento 
de todas as suas particularidades, a fim de que possam ser traduzidas sem, no entanto, perder suas características mais relevantes.

Assim, a linha inscrita em uma superfície de maneira sintética é portadora de grande expressividade; como se tivesse condensado em si todo um universo que fica manifesto através de sua presença simples e concisa. Em desenhos figurativos, alguns artistas conseguem, por meio da economia de linhas, configurar imagens densas, dando conta de apresentar muitas especificidades do motivo desenhado. No desenho realizado por Iberê Camargo em 1993, em que o artista retrata o seu gato Martim, nota-se que a linha é conteúdo da obra tanto quanto a sua temática. o uso reticente da linha contínua e limpa parece representar a figura em sua essência. A maneira como o artista conduziu o instrumento sobre o papel, bem como a sua gestualidade, evidenciam-se no desenho e reforçam sua potência expressiva. Percebe-se que o traço, ainda que cumpra a função representacional, não se encontra subordinado a retratar a figura, assume sua presença linear como elemento da linguagem do desenho. 


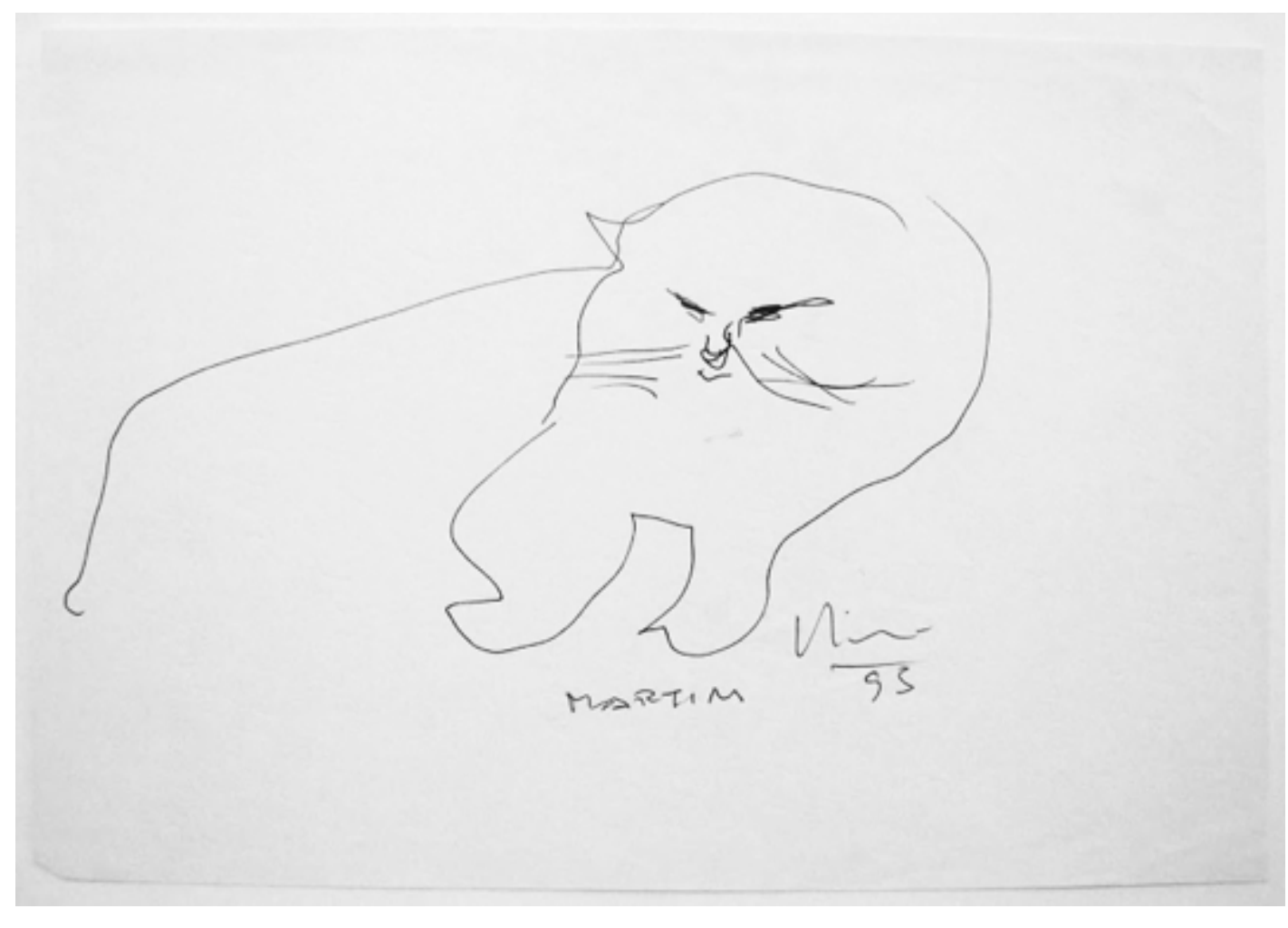

Iberê Camargo. Martim, 1993. Nanquim sobre papel.21,6×31,5

A interlocução entre artista e o desenho no momento mesmo de sua concepção parece ocorrer num fluxo mais contínuo, se comparado a outros meios de criação artística como, por exemplo, pintura, gravura ou escultura que requerem um preparo prévio de seus materiais. Segundo Icleia Cattani" " "o desenho é, talvez, a linguagem de arte primeira no espaço bidimensional próxima do corpo e de seus movimentos naturais, necessitando poucos recursos técnicos e escassos materiais". (CATTANI, 2002:25).

Analisando a obra de Eliane Chiron", cujo processo é definido pela própria artista como sendo uma prática do lacunar, Cattani comenta:

o desenho talvez seja a linguagem na arte mais próxima dos sentidos e dos sentimentos, o que demanda

3 Icleia Cattani Crítica de Arte é pesquisadora e docente orientadora do PPG-Artes Visuais do IA - UFRGS

4 O trabalho citado da artista consiste numa proposta de realizar um desenho por dia ocupando as páginas de face em ordem sequencial de um caderno de desenho. (CATTANI,2005:25) 


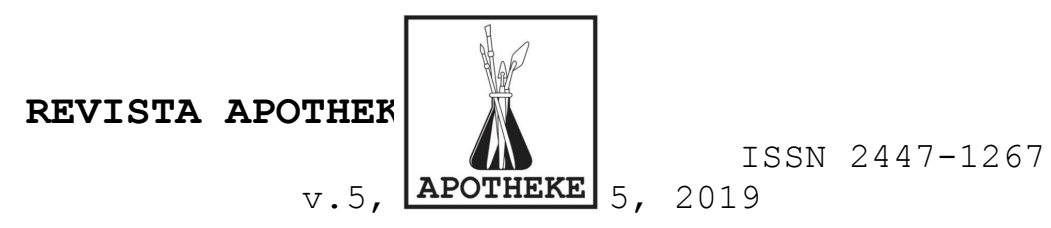

simultaneamente o exercício do rigor. Mergulhar nas
profundezas do gesto e, depois, não só voltar à
superfície, mas afastar-se ainda mais, para compreender
e analisar criticamente o já feito: [...] Entre o
realizar e o analisar, estão as correções do percurso, o
refazer, o retomar - ou o abandono daquilo que não
corresponde ao que se deseja e a procura de algo novo.
(CATtANI, $2005, \mathrm{p} .30$ )

No processo de imersão no desenho há um sentido de lançarse ao novo; abrir mão do já conhecido, do terreno firme e nos aventurarmos a terras que podem vir a ser movediças. 0 processo de criação se dá por contaminação, no sentido de que abrimos mão dos nossos pré-conceitos, possibilitando caminhar para que o novo possa se instaurar em nós e na obra.

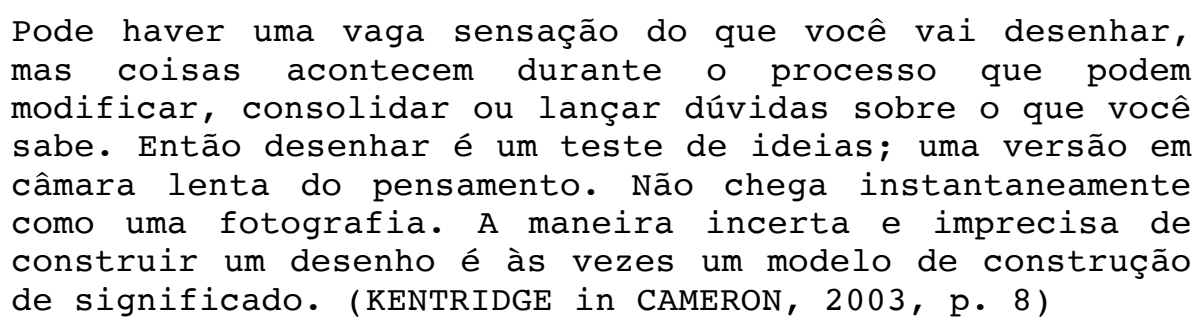

Sair de um ponto, objetivando chegar a outro determinado, previamente, não condiz com a criação em arte. Nas idas e vindas do ato de criação, o artista processa a obra e se deixa processar por ela. (PAREYSON, 1993:20) ${ }^{5}$

Outra característica do desenho é a de ser um meio que não vela seu processo de construção, permitindo que se perceba o tipo de gesto empregado na sua execução. Contundência, leveza, amplitude nos movimentos, bem como intensidade dos gestos são dados expressivos no desenho.

Por sua origem ter sido historicamente ligada à função de esboço e projetos, geralmente realizados em escalas menores, absorvemos a noção de que o desenho resulta de gestos contidos e controlados. Em relação aos movimentos adotados no ato de escrever, percebe-se haver um tipo de gesto cuja rotação provém do pulso, uma vez que seu objetivo é a legibilidade. 5 Pareyson aborda essa questão detalhadamente em sua Teoria da
Formatividade. 


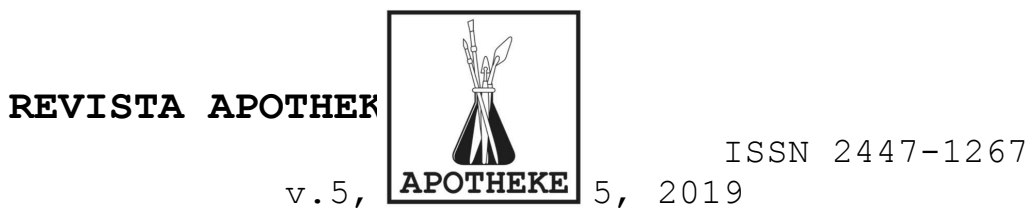

Entretanto, é interessante pensar sobre outras relações ou possibilidades dos gestos aplicados na ação de desenhar.

o gesto mais convulsivo, a ação mais desordenada deixa
sempre uma marca de sua própria ação, nos retrocede ao
momento mesmo em que realizamos; cada um de seus traços
torna evidente a velocidade, as dúvidas e a ansiedade
com que foram executadas, nos <representam> novamente.
Tornam visível o tempo mesmo da ação que o realiza. A
ação de desenhar representa a nós mesmos na ação de
representar, clarifica os itinerários da nossa
consciência, fazendo-se evidente ante nós mesmos.
(MOLINA, 2006, p. 49)

A partir do momento que o desenho conquista autonomia como linguagem artística, percebemos nas obras de alguns artistas a adoção de suportes maiores e, como consequência, traços amplos que depõem da ação proveniente de todo o corpo do artista, o que amplia o repertório desse meio de expressão.

Considerando os diferentes tipos de instrumentos de inscrição utilizados para desenhar, encontramos o lápis como sendo o mais comum e usual, já que é um instrumento ao mesmo tempo preciso e sensível; o grafite se deposita na porosidade do papel e vai sendo conduzido de forma a percorrer trajetos ou preencher áreas na sua superfície. A contundência do traço, sua espessura ou leveza é decorrente da pressão colocada no instrumento ao fazermos uma inscrição em dada superfície. De acordo com Catherine De Zegher ${ }^{6}$ :

A linha pode ser quebrada ou contínua, pode incluir e estender a sequência de riscos únicos ou uma faixa ininterrupta. É na relação de uma marca a outra, nas suas gradações de tons, que o desenho adquire forma, profundidade, volume. Durante séculos, pode dizer-se, foi estabelecido certo equilíbrio entre a linha e traço, no sentido de que a linha, o princípio fundamental, definia substancialmente o contorno da figura, enquanto que os traços de modelagem sugeriam um grau de espacialidade e impressão tátil. Juntos, eles induziram uma sensação de movimento e energia; com os traços como meio de nuance, vitalidade e instabilidade. O ideário mental da linha de contorno foi complementado pelo destaque concreto de pequenas marcas individuais. (DE ZEGHER, 2010 , p. 23 ).

6 Catherine de Zegher (Groningen, Países Baixos) é curadora internacional, crítica de arte moderna e contemporânea e historiadora de arte. 
REVISTA APOTHEK

De Zegher aponta para 0 fato de que historicamente 0 desenho de contorno precede às questões da perspectiva. A linha de contorno que apreende a forma dá conta exclusivamente da analogia, da parecença. "A combinação de delineamento e perspectiva permite que objetos no espaço real sejam transcritos para o plano imaginário". (DE ZEGHER,2010, p. 23). o traço aparece com o potencial de mostrar a espacialidade da figura, de representar sua volumetria e ocupação no espaço. Assim, uma série de marcas juntamente dispostas como, por exemplo, em hachuras ou sombreados, estariam atribuindo corporeidade àquilo que a linha define pelo delineamento.

\section{DESENHO CONTEMPORÂNEO}

$\mathrm{Na}$ contemporaneidade temos visto muitos desdobramentos das modalidades da tradição das artes. As fronteiras que separavam os meios, de forma muito marcada, afrouxam os seus limites e assim se conquista um terreno propício à manifestação do hibridismo em certas produções artísticas.

Retomando o comentário de Catherine De zegher sobre o potencial da linha e do traço, apresento aqui alguns artistas contemporâneos que expandem os preceitos tradicionais da linguagem do desenho.

A artista belga Edith Dekynd, no desenho intitulado Drawing 003, inscreve insistentes marcas de grafite ao ponto que esses mesmos traços desaparecem e configuram uma massa com pigmentação uniforme, porém, nessa mesma obra, a contundência e repetição dos traços formam rugosidades na superfície do papel, tanto que perde sua planaridade. Percebe-se que a extensão do campo do desenho se dá aqui no suporte: na sua materialidade e na dissolução do traço. 

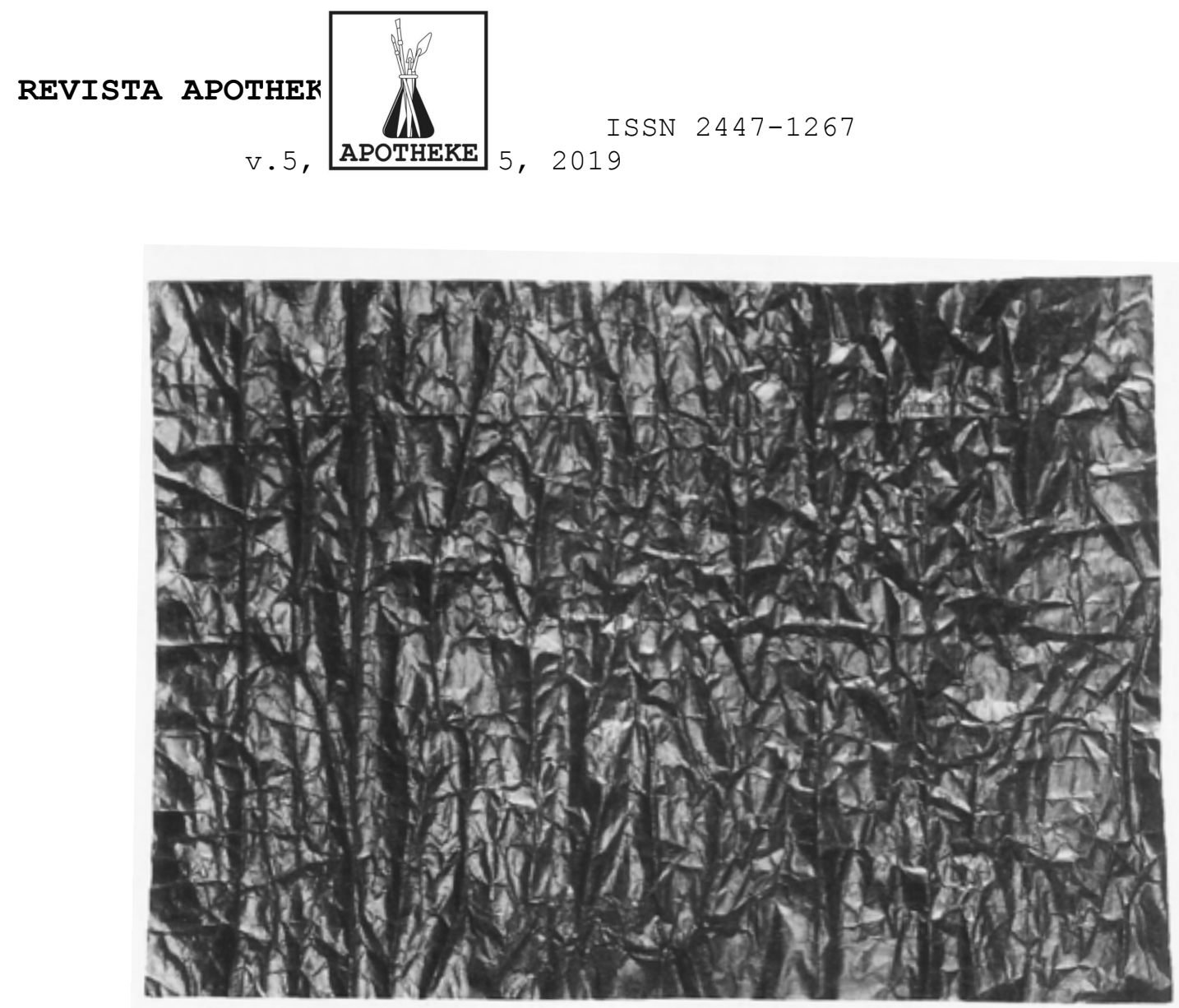

Edith Dekynd. Drawing 003, 2009. Grafite sobre papel $47 \times 65 \mathrm{~cm}$

Richard Tuttle, artista americano, traz em seu trabalho denominado de 44th Wire Piece do ano de 1972, o que poderia ser considerado um comentário sobre três instâncias da linha: aquela que possui materialidade (fio metálico), a que se inscreve no suporte por meio de um instrumento que nesse caso é o grafite. $E$, o terceiro modo de aparição da linha se dá na sua imaterialidade, uma vez que ela se apresenta enquanto sombra da linha de metal projetada na parede. Vemos, então, um diálogo travado entre materialidade, representação e virtualidade. 
REVISTA APOTHEK

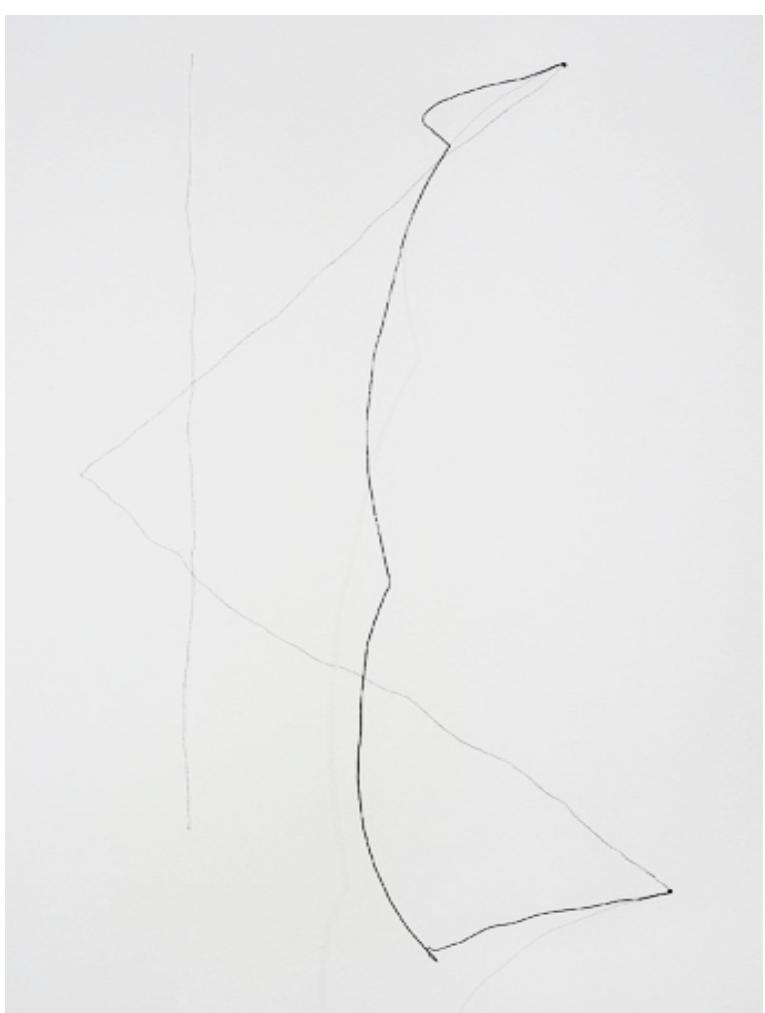

Richard Tuttle. 44th Wire Piece, 1972. Fio, prego e lápis sobre parede. 47 $\mathrm{x} 22 \times 11 \frac{1}{4}$

O Artista inglês Fred Sandbcak trabalha com a noção da linha de contorno. Dispõe em três paredes de uma sala de exposição, três fios de acrílico esticados; dois deles dispostos verticalmente em paredes opostas e, o último, tensionado horizontalmente de modo que coincida com as pontas das duas linhas que estão na vertical, à altura do chão. As três linhas dispostas dessa maneira criam um plano transparente e ilusório que obstruiria a sala, caso sua existência fosse material. 

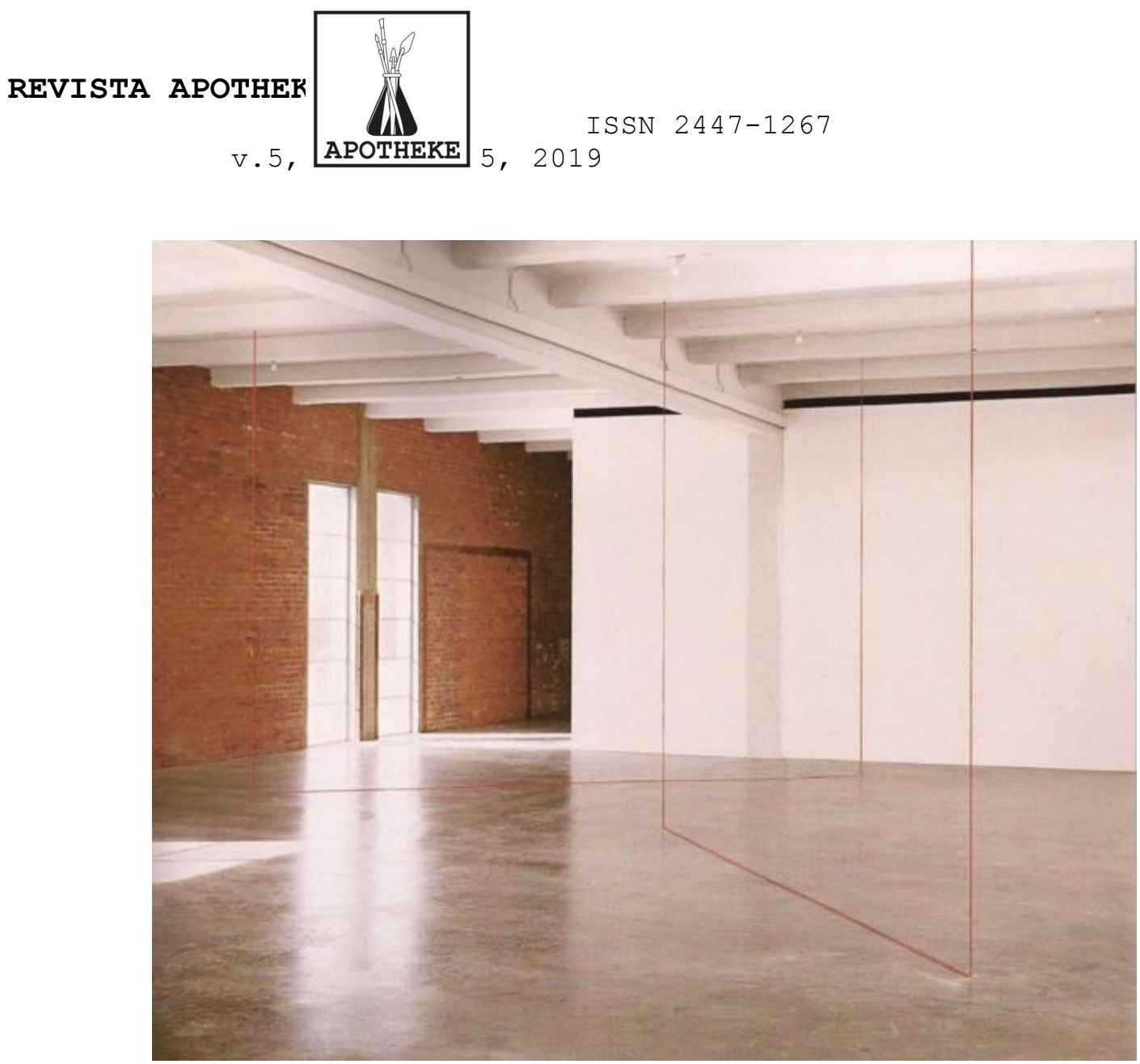

Fred Sandback. Sem título, 1997. Construção vertical em duas partes, fio acrílico vermelho

\section{CONSIDERAÇÕES FINAIS}

O desenho é uma forma de comunicação antes mesmo de ter sido considerado arte. A diferença está que, no desenho artístico há a intenção de ir além do indicar e informar.

Desenhar, operando pela via do acerto e erro se opõe aos princípios desse meio. Por ser um ato criativo de grande amplitude, o desenho não nos aponta uma única resposta.

Os conhecimentos que carregamos enraizados, quando não postos em xeque passam a ser frágeis e anacrônicos; frágeis, no sentido de que impossibilitam a visão das diversas facetas dos fenômenos do mundo. Corremos o risco de ficarmos aprisionados em certezas sedimentadas. Tendo em conta que desenhar é dar um salto ao desconhecido, arriscar-se ao novo, o que se pode ter como resultado além de uma imagem é a 
REVISTA APOTHEK

ampliação do nosso universo, como também o alargamento de fronteiras.

Não raro, as pessoas comentam suas dificuldades, afirmando inclusive que não sabem desenhar. Considerando que desenhar é uma extensão do pensamento, aquele que pensa sabe desenhar. 0 desenho é um meio de expressão ao qual nos lançamos com algumas expectativas prévias, mas que durante o seu processo de feitura acolhe mudanças de rumo, alterando os objetivos inicias, o que acende novas perspectivas ao seu andamento e finalização.

É importante reconhecer o uso que fazemos da linha em vários setores das nossas vidas, quer sejam aquelas traçadas mentalmente, que nos situam no tempo e no espaço como as inscritas que, visualmente, mostram-nos e nos orientam em percursos e rotas. Identificar a presença do desenho nas variadas operações que realizamos no dia a dia poderá tornarnos conscientes da proximidade e intimidade que temos com tal pensamento gráfico, desmistificando o ato de desenhar.

\section{REFERÊNCIAS :}

BENJAMIN, Walter. Sobre a Pintura ou Sinal e Mancha. in: MOLDER, Filomena. Matérias Sensíveis. Lisboa: Relógio D' Agua Editores, 1999.

BUTLER, Connie e DE ZEGHER, Catherine. On line: Drawing trough the Twentieth Century. Publicado por The Museum of Modern Art, Nova York, 2010. BROOKS, Alfred. Drawing. in The Art Bulletin vol. 2, n.3. New York: College Art Association, março de 1920).

CATTANI, Icleia. o desenho como abismo. in Revista Porto Arte v 13, no $23-$ Porto Alegre, 2005. Universidade Federal do Rio Grande do Sul. Instituto de Artes.

DUZzo, Flávia. Ausências no desenho: áreas de não desenho, apagamento e desgaste. Tese de Doutorado. Universidade Federal do Rio Grande do Sul Instituto de Artes - Programa de Pós-graduação em Artes Visuais, Porto Alegre, Brasil. 2014 .

GODOY, Vinícius. Iberê. Influência é desenho. Tese de Doutorado. Universidade Federal do Rio Grande do Sul - Instituto de Artes - Programa de Pós-graduação em Artes Visuais, Porto Alegre, Brasil. 2009 .https: / / lume.ufrgs.br/handle/10183/2/browse? type=author $\&$ value=Godoy $\% 2 \mathrm{C}$ +Vin。C3\%ADcius+Oliveira. Consulta: 05/07/2019

HOUAISS, Antônio. Dicionário Houaiss da Língua Portuguesa. Rio de Janeiro, Ed. Objetiva, 2009 .

MOLINA, Juan José Gómez. Las lecciones Del dibujo. Ediciones Cátreda. Madrid-Espanha, 2006.

PAREYSON, Luigi. Teoria da Formatividade. Rio de Janeiro:Vozes, 1993. 
TONE, Lilian(org.) William Kentridge Fortuna. Catálogo da exposição, 2012. VINCI, Leonardo da. The Notebooks of Leonardo Da Vinci.

https: / / books.google.com.br/books? id=8151FQ3RH5UC\&pg=PA 4 \&lpg=PA4 $7 \& d q=l e o n a$ rdo+da+vinci+definition+of+the+nature+of+line\&source=bl\&ots=qWcrkf $3 v 8 p \& s i g=$ ACfU3U1m6aosMoAt0qz imAycP6a39 KEnfw\&hl=pt-BR\&sa=X\&ved=2ahUKEwi-

$4 \mathrm{v} 2 \mathrm{UzKr} j \mathrm{AhX} 4 \mathrm{GrkGHO} 0 \times \mathrm{XBeQQ} 6 \mathrm{AEWEXOECAOQAQ \# v=onepage} \& \mathrm{q}=1$ leonardo $\% 20 \mathrm{da} \% 20 \mathrm{vinci} \% 20$ definition $\% 200 f \% 20$ the $\% 20$ nature $\% 200 f \% 201$ ine $f=f a l s e$

Endereço eletronico do lattes: http://lattes.cnpq.br/2680563666554583

Doutorado em Artes Visuais (poéticas visuais) ppgav - UFRGS/RS (2014), com pós-doutorado em Artes Visuais- UDESC (2017). Mestrado em Artes Visuais (teoria e crítica) ppgav - UDESC/SC (2007) e bacharelado em Artes Plásticas - UFRGS/RS (1984). Professora, pesquisadora e artista. Participacão do grupo de pesquisa Estúdio de Pintura Apotheke.

Recebido em 05 de agosto de 2019 Aprovado em 16 de agosto de 2019. ORCID: https://orcid.org/0000-0003-2241-0599 